\title{
Evaluation of Open Innovation in B2B from a Company Culture Perspective
}

\author{
Nikolaos Katsikis ${ }^{1}$, Alexander Lang ${ }^{2}$, Csaba Debreczeny ${ }^{3}$
}

\begin{abstract}
This article is written for innovation managers, business developers or employees in similar positions in a company selling in a B2B environment. Decision criteria are presented which will help to find the right open innovation tool for the desired goals and also for the given company culture. Aiming to increase business successfully by involving externals cannot be seen independently of the attitude and openness of an organization as a whole to this approach.
\end{abstract}

Keywords: Open Innovation; B2B; Decision Criteria; Innovation Culture; Company Culture

Submitted: June 29th 2016 / Approved: September 12th 2016

\section{Introduction}

The use of open innovation for business development in the B2B industry sector still cannot be considered as daily business, different to $\mathrm{B} 2 \mathrm{C}$, where customer feedback and integration has become an integrated part. However, according to Chesbrough and Crowther (2006) even traditional and mature industries can profit from open innovation. Skepticism and lack of experience are major hurdles, and they can be overcome more easily by companies with foreign market activities (Abulrub and Lee, 2012). However, this does not mean that open innovation is done primarily on a global scale. Their study reveals that these firms are simply more open to external sources. According to Pilav-Velic' and Marjanovic (2016), a company philosophy open to collaboration with external partners can also have a positive impact on business process innovations, leading to a higher probability for the successful introduction of radical innovations. Open innovation can be used for problem solving either locally or distantly, in an experiential or cognitive way, which is described in detail by Lopez-Vega et al. (2016). It is important to note that they do not distinguish between a good or bad pathway. Instead, the optimum solution depends on the objective, for instance in terms of timescale or the expected outcome, e.g. incremental or disruptive innovation.

Having said this, it must be noted that even for collaborative and globalized companies the jungle of open innovation cannot be entered easily. This especially counts for companies in a B2B environment. The following overview and qualitative evaluation $\mathrm{c}$ an be seen a a guideline to innovation managers responsible for deciding which methodology to use. Not only do the desired output and the acceptable input, especially in terms of time and money, have to be taken into account. The culture of the company is a very decisive factor when it comes to the use of open innovation.

\section{Methods}

In this chapter a short introduction to the open innovation methods discussed in the paper is given. The authors do not intend to give an instruction on how to use the tools in detail, but rather aim at giving a definition for each method.

\section{Bilateral Innovation Workshop:}

According to Gersbach (2004) bilateral innovation is a process which both partners benefit from. Bilateral innovation projects will only be successful if the participating companies have a very close relationship or a willingness to build it up. The latter is valid if the approach is started by the top management of the participating companies. In other cases at least one internal champion in each organization has to be found who first promotes the cooperation internally, and then keeps up the conversation and does the ongoing planning with the partner. The method of "Bilateral Innovation Workshops" is very successful if used for information exchange between the members of a supply chain. Doing so, the workshop would be beneficial to both parties (Mitussis, 2010). In practice a "Bilateral Innovation Workshop" goes much beyond regular conversation between customer and supplier, which in many cases means a limitation on the exchange of information of members of the purchasing and the sales department on specific issues. An Innovation WS acts differently regarding people and topics. It brings together engineering, product management, front sales, marketing and decision makers to discuss predetermined topics, which purposely are not limited to existing products or business. It can be designed like a roadshow, i.e. the supplier presents new ideas, products, and services etc. as a basis for discussions. Alternatively, it starts with technology and market trends, and from there collaboration opportunities are derived.

(1) H.C. Starck Ceramics GmbH, Lorenz-Hutschenreutherstr, Germany

(2) IMAN Solutions GmbH, Boosstraße, Germany

(3) Pannon University, Hungary

*Corresponding author: nikolaos.katsikis@hcstarck.com 


\section{Innovation Journey:}

The innovation journey, a methodology which guides the innovation process in companies, is often described as a nonlinear cycle of divergent and convergent activities that may repeat over time and at different organizational levels if resources are obtained to renew the cycle. The methodology maps the innovation process in a company and describes it from the initiation to its termination (Van de Ven, 1999). The journey is a descriptive name for a long-term process, starting with the company's internal preparation and ending with business opportunities. However, different to the bilateral WS the partners are often non-customers and the applications and potential products are hardly ever specified in the beginning. Finding an "internal champion" who promotes such a journey is not always easy. Teaser presentations incorporating news and information interesting for the partner can be used as a starting point. During the whole journey the goal of both parties is not primarily to do business together but also to understand market demands, unfulfilled needs, products, technology and applications better. Other methods introduced in this paper such as certain workshops can be integrated in the "Innovation Journey" as active sessions in order to generate ideas or to enlarge the network and knowledge base. This also includes an enlargement of the participant base beyond the two companies active in the journey.

\section{Lead User Workshop:}

Combining solution and need information not only in one workshop but also in one person is the principal benefit of the lead user concept. To invite many of those combined talents to a workshop provides the opportunity to identify needs and find market orientated solutions within $2-3$ days. Finding the right participants and extracting the sticky information from them is hard work (von Hippel, 2008). In literature a lead user is defined by "his/ her leading edge position on an important market trend" and "his/ her level of expected benefit from an innovation" (Hienert, 2007). With his knowledge a lead user may also provide ideas to improve products. According to Lüthje (2004) the lead user method allows to include user experiences into the design process. The user experience does not come from a wide field of different customers, but from customers that are "ahead of the market" (Lüthje, 2004). The lead user's market origin and source of benefit influences the novelty of the products greatly (Hienert, 2007). In the further development of the lead user concept after 2000 it was shown that lead users do not have to be from the target market, but can also be from markets with similar requirements (Lilien, 2002). A large benefit of the method is that lead users are able to create new concepts much faster than traditional methods (Herstatt, 2003) and that the method is applicable to various different industries (Hienert, 2007). The lead user method usually consists of four phases. The first phase is also the initiation of the lead user process. In it an interdisciplinary team is formed, the target market is defined and the goals of the method are defined. In the second phase, the needs and trends in the market are identified. This is done by interviews with experts, the scanning of the literature, the Internet and databanks. Then the most attractive trends are selected. The third step consists of the search for lead users and their identification. The search is done by methods based on networking like broadcasting. Analogous markets can also be investigated. In the fourth and final phase, the concept design is developed. Finally, the workshop with the lead users is held to generate or to improve existing product concepts (Lüthje, 2004).

\section{Cross Industry Workshop:}

The Cross Industry Workshop works best when integrating at least three different parties originating from various industry sectors and which intentionally have no or very limited overlap between their business. Gassmann et al. (2012) show that workshops also among suppliers and customers are beneficial to integrate partners along the value chain. Creativity derives from the transfer of existing and approved processes, products and business models. The ideas generated do not have to lead to a relationship between the partners, but instead each partner can make use of ideas and key learnings for their own benefit. Support and input can come from additional scientific partners, i.e. from universities or institutes. Also a neutral moderator is recommended for maximum output. In a second step a validation of the ideas becomes necessary which can continue in an open innovation approach with the same or new partners.

\section{Idea Contest:}

An idea contest is mainly an online method for a certain period of time, usually restricted to one specific topic (Bullinger, 2010). The task to be worked on can differ from textual descriptions to prototypes or even fully functional solutions (Bullinger, 2010). Usually some kind of reward (intrinsic or extrinsic) is offered to the winner at the end of the contest. According to Bullinger (2010) table 1 shows design elements for idea contests and their common attributes. As Cooper showed in 2008, idea contests were not a very popular Open Innovation method at that time. Only less than $5 \%$ of the corporations were using it. In many cases the task to be worked on is limited to simple consumer products. One of the major benefits is the massive marketing impact documented by the integration of many users, but as Cooper emphasizes, there is always the downside of the enormous cost of setting up an idea contest (Cooper, 2008). 
Table 1: Design elements for idea contests and their common attributes (according to Bullinger, 2010)

\begin{tabular}{|c|c|c|c|c|c|c|c|}
\hline Design element: definition & \multicolumn{7}{|c|}{ Attributes } \\
\hline Media: environment of IC & \multicolumn{2}{|c|}{ Online } & \multicolumn{2}{|c|}{ Mixed } & \multicolumn{3}{|c|}{ Offline } \\
\hline Organizer: entity initiating IC & \multicolumn{2}{|c|}{ Company } & \begin{tabular}{|c|} 
Public \\
organization
\end{tabular} & \multicolumn{2}{|c|}{ Non-profit } & \multicolumn{2}{|c|}{ Individual } \\
\hline \multirow{2}{*}{$\begin{array}{l}\text { Task/ Topic specificity: solution space of } \\
\text { IC }\end{array}$} & \multicolumn{2}{|c|}{ Low } & \multirow{2}{*}{\multicolumn{2}{|c|}{ Defined }} & \multirow{2}{*}{\multicolumn{3}{|c|}{ High }} \\
\hline & \multicolumn{2}{|c|}{ (open task) } & & & & & \\
\hline $\begin{array}{l}\text { Degree of elaboration: required level of } \\
\text { detail for submission to IC }\end{array}$ & Idea & Sketch & $\begin{array}{l}\text { Con- } \\
\text { cept }\end{array}$ & $\begin{array}{l}\text { Proto- } \\
\text { type }\end{array}$ & Sol & tion & $\begin{array}{l}\text { Evol- } \\
\text { ving }\end{array}$ \\
\hline $\begin{array}{l}\text { Target group: description of participants of } \\
\text { IC }\end{array}$ & \multicolumn{3}{|c|}{ Specified } & \multicolumn{4}{|c|}{ Unspecified } \\
\hline $\begin{array}{l}\text { Participation as: number of persons } \\
\text { forming one entity of participant }\end{array}$ & \multicolumn{2}{|c|}{ Individual } & \multicolumn{2}{|c|}{ Team } & \multicolumn{3}{|c|}{ Both } \\
\hline Contest period: runtime of IC & \multicolumn{2}{|c|}{ Very short term } & Short term & \multicolumn{2}{|c|}{ Long term } & \multicolumn{2}{|c|}{$\begin{array}{l}\text { Very long } \\
\text { term }\end{array}$} \\
\hline $\begin{array}{l}\text { Reward/motivation: incentives used to } \\
\text { encourage participation }\end{array}$ & \multicolumn{2}{|c|}{ Monetary } & \multicolumn{2}{|c|}{ Non-monetary } & \multicolumn{3}{|c|}{ Mixed } \\
\hline $\begin{array}{l}\text { Community functionality: functionalities } \\
\text { for interaction within participants }\end{array}$ & \multicolumn{3}{|c|}{ Given } & \multicolumn{4}{|c|}{ Not given } \\
\hline $\begin{array}{l}\text { Evaluation: method to determine ranking } \\
\text { of submissions to IC }\end{array}$ & \multicolumn{2}{|c|}{ Jury evaluation } & Peer review & \multicolumn{2}{|c|}{$\begin{array}{c}\text { Self- } \\
\text { assessment }\end{array}$} & \multicolumn{2}{|c|}{ Mixed } \\
\hline
\end{tabular}

Practical experience shows, idea contests are often the invitation to externals to answer specific questions or do tasks in a certain way. Depending on the type of contest the ideas of others are visible for anyone or not, ideas can be brought to the next level on top of ideas of others, also sometimes externals are allowed to vote and select the winners. The legal issue is very critical here, as the IP situation is tricky: if the idea is visible on the Internet to anyone, it becomes state of technology. Another option is to transmit ideas within a closed community only with some NDA-rules. This way they can still be patented, but the question is by whom, which depends a lot on the details of the proposed idea compared to the patent claims. The information provided to the community up-front, the definition of the task and the template for the answers are very crucial for the quality of ideas developed in this process

Table 2: Output / Effort Matrix for Selected Open Innovation Methods based on the experience of the authors.

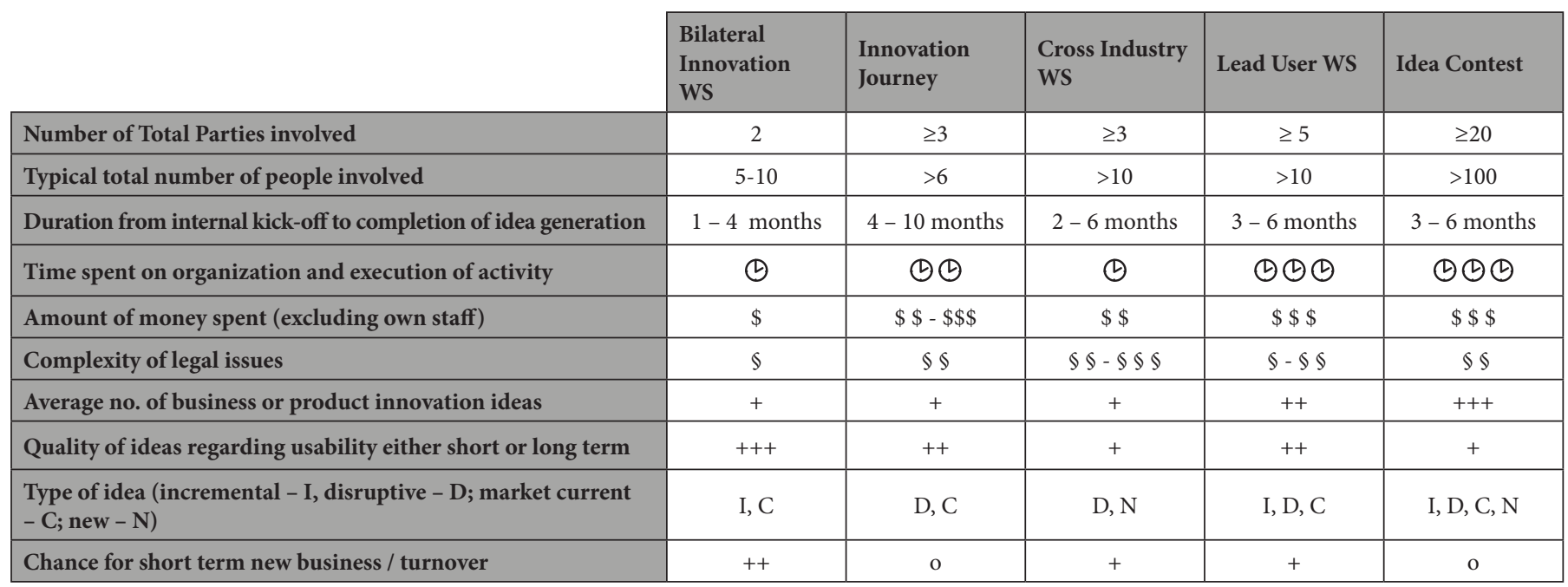

'o' means not relevant

't' means low

' ++ ' means medium

'+++' means strong / high 


\section{Cultural Aspects}

Besides the benefit / effort matrix summarized in the table above a very important further issue must be taken into consideration for the decision on which methodology to be chosen: the company's innovation culture. According to Meyer (2014) four types of innovators can be identified, depending on the degree of innovation and the innovation speed:

i) "Proactive Innovators" who are pioneers for further development,

ii) "Strategic Innovators" who usually experience a strong leadership and thus innovation is seen as top down approach

iii) "Innovative Optimizers" who focus on incremental innovation and

iv) "Operative innovators" who have a creative potential, however, they focus on core operational business and processes and lack strategy beyond these topics.
Not every culture category can handle all open innovation approaches discussed in this report. And this is not necessary anyhow, as the goals are different and so is the expected outcome of the methods. In Figure 1 the fit of the above introduced open Innovation methods to the company culture types according to Meyer (2014) is shown. "Operative innovators" in principal have limited interest in external input, especially regarding disruptive or new ideas. The only tool of value for this group are bilateral innovation workshops as their output focuses on incremental ideas valuable for the current market but with only small budget and time input. On the other hand, all methods are valid for "Proactive Innovators", especially innovation journeys and cross industry workshops as they allow for mid- and long-term approaches not only limited to product ideas but also taking into account new business strategies and cooperations. The results for the "Strategic Innovators" are similar, however, as they want to keep control over the whole process their fit is a little bit more limited to those methods focusing on disruptive ideas. "Innovative Optimizers" have a strong focus on lead user and bilateral workshops as in both methods the targeted business, product or process can be well defined upfront and the benefit/effort ratio is optimal.

Figure 1: Fit of Selected Open Innovation

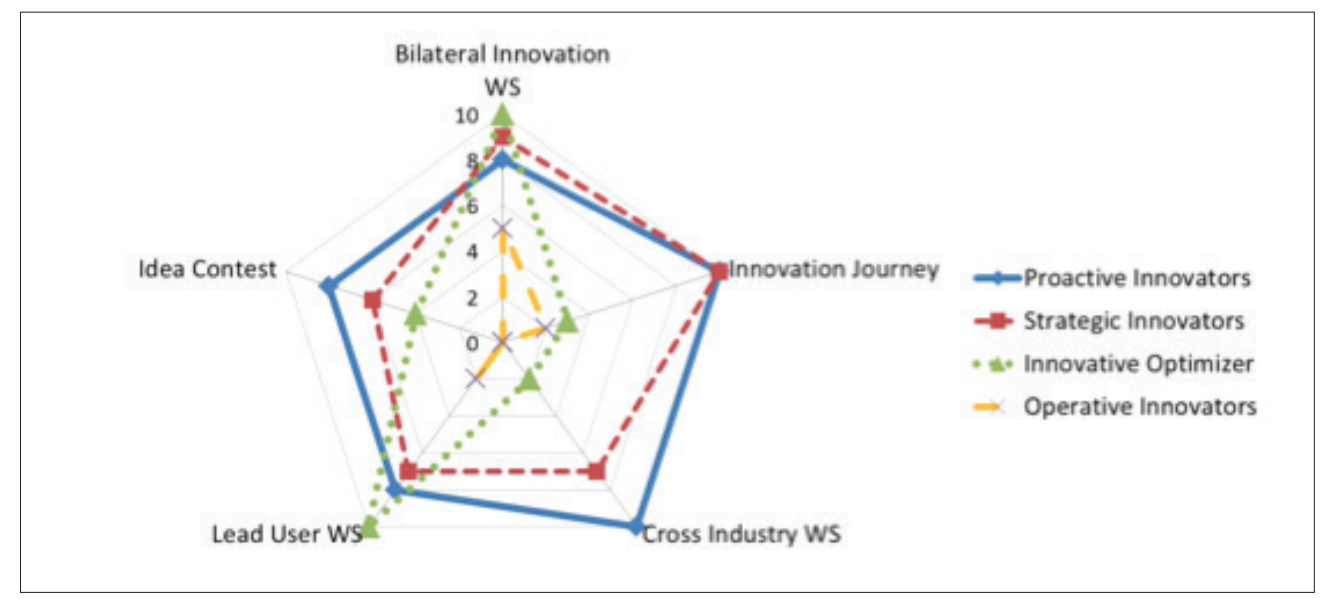

The opennes for external input of the company as a whole is crucial for a successful open innovation approach. On top of that the individual employee is either a limiting or driving force as described in detail by Salter et al. (2015). The ideation performance of scientists and engineers correlates with the use of external sources of knowledge. Thus the quality of the output and the commercial success coming from open innovation tools depends to some extend on the indiviual.

A further issue is the need for a presence of a permeable innovation funnel in two directions:

\section{i) Outside-In}

Ideas from outside have to be identified and then to be integrated into the organization's R\&D funnel. This does not end with the presentation to the team. The company's culture must allow for external input to be built on. The "NotInvented-Here"-Syndrom has to be overcome, i.e. typical reactions such as the listing of reasons why the idea will fail instead of constructive adjustments. Especially "Operative Innovators" and "Innovative Optimizers" tend to block ideas from outside. Furthermore, an internal champion, a team or a certain process needs to be established in order to have a clear responsibilty on who takes care for external input. Time and ressources have to be allocated before even starting an ideation WS or any other tool. Otherwise the momentum from such an event cannot be transferred into the stage-gate pipeline of the internal innovation management process.

ii) Inside-Out

On the other hand, product or business model innovation ideas should be able to leave the boundary of the company. Otherwise a mismatch with the traditional habits or current customer and product base would lead to a dead end. The 
inside-out transfer means a change in the conventional pathways of the company and requires the need to think out of the box. New opportunities can be harvest by entering new applications or markets, changing sales structure, service level or value chain integration, opening new business lines or creating joint ventures or even spin-off. Leaving the comfort zone is the buzz word for helping achive a breakthrough. It is important to mention that this should be clear and thus prepared before starting an open innovation project. Otherwise not only the company will miss chances but also the external partner in the innovation process will get dissapointed as their needs and requirements are not met as expected.

Figure 2: Outside-In and Inside-Out stage Gate Process for Sucessful Open Innovation Integration

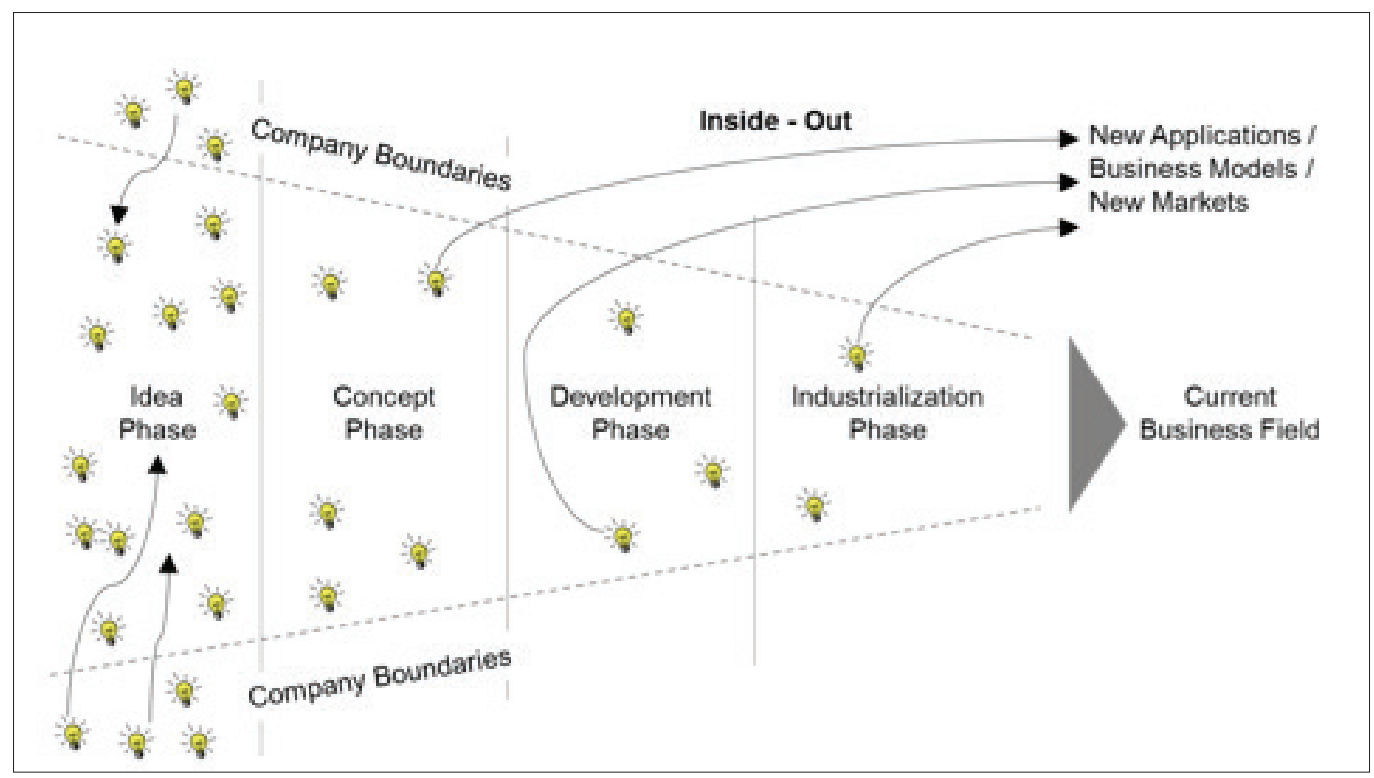

\section{Motivation and Topic Search}

Typical reasons for companies to involve externals into their development process are summarized in Table 3. On purpose the motivation is seen from the perspective of the internal champion triggering and pushing the open innovation approach. Especially if these methods are new to a company, the hurdles will be numerous and without the right attitude and intrinsic passion they will not be completed. The main drivers for open innovation can come from marketing, sales or top management as they deal with externals each day anyhow and as such have access and more feedback already. The R\&D department is a common source also, as innovation is their daily business. Production is not mentioned as their job is to make the current products and not to develop the next generation. Business Development, Strategy or other departments fall between sales, management, marketing and R\&D depending on the definition within the company and thus are not listed here.

Table 3: The different Motivations to do Open Innovation by the different Department

\begin{tabular}{|c|c|c|c|}
\hline Top Management & Research \& Development & Sales & Marketing \\
\hline $\begin{array}{l}\text { New tool to achieve the strategic } \\
\text { goals such as turnover, new product } \\
\text { sales etc. }\end{array}$ & $\begin{array}{l}\text { Method to close internal gaps coming } \\
\text { from reduced budgets by externals }\end{array}$ & $\begin{array}{l}\text { Increased turnover by new } \\
\text { products / new customers / new } \\
\text { business model }\end{array}$ & $\begin{array}{l}\text { Chance for publicity e.g. via open } \\
\text { Idea Contest or via press releases } \\
\text { regarding joined development }\end{array}$ \\
\hline $\begin{array}{l}\text { Head start compared to colleagues } \\
\text { leading other businesses within the } \\
\text { same company or external leaders. }\end{array}$ & $\begin{array}{l}\text { Shorter innovation cycles (expected by } \\
\text { management due to market demand or } \\
\text { forced by strong competition) }\end{array}$ & $\begin{array}{l}\text { More profitability via innovative } \\
\text { products or new business models }\end{array}$ & $\begin{array}{l}\text { Relationship build-up, Networking, } \\
\text { Customer loyalty }\end{array}$ \\
\hline
\end{tabular}


Finding the right topics and the best matching external partners is the key to using open innovation methods efficiently. But what criteria are to be used to identify the optimum topic? Different approaches have been established, which vary in effort for preparation and evaluation as well as room for specific or more general expected outcome. Some will be explained in the following:

\section{1) From Mega-Trends to Search Field}

The approach starts with mega-trends such as climate change, urbanization, lack of resources, digitalization etc. From there industry trends have to be derived especially via interviews in various industry sectors. The focus should be on the question how the mega-trends will influence the availability of raw materials, the production process, the legal boundary conditions or the markets served. This will lead to a list of unfulfilled needs and requirements which can be matched with one's own current or desired competences to find the optimum starting points for a search field, which determines the topic of the open innovation activity. This approach is especially suitable for "Strategic Innovators" and "Proactive Innovators".

\section{2) Micro-Trend Clustering for Inspiration}

Especially if the involvement of externals via interviews already in the phase of finding the right search field is not suitable, micro-trend clustering is an interesting alternative. Various companies offer data-bases of trends in research or industry regarding products, processes, business models or other issues. They are called "micro-trends" as they are usually quite unique, local or outstanding and it cannot be predicted whether they will succeed or not as they have just started. You can look for attractive or matching micro-trends and cluster them, on your own or with the support of such trend-searchcompanies. This will allow getting a more independent and secure view on how stable or important certain trends will be. The open innovation activity will be related to the cluster. Again this approach is especially suitable for "Strategic Innovators" and "Proactive Innovators".

\section{3) Technology Development Driven}

Another very reasonable way to find the right topic is to look at your last developments and the markets behind them. Is there room for more as the company is still a newcomer in the field or the application is still growing and, therefore, still changing its needs and demands? Of course this method will most likely stay closer to the existing business than methods 1) and 2), but on the other hand, the effort to get a starting point is far lower and also the search for the right partners will be a lot easier as major players are already known and also existing customers can be chosen. This approach is especially suitable for "Innovative Optimizers" and also for "Operative Innovators".

\section{Conclusion}

Open innovation is an umbrella term for very different methodologies to get in contact with externals to achieve specific goals together. The main focus is typically on products and services, but also processes or business models can be discussed. The success of these activities depends strongly on the innovation culture of the company because the cost/benefit ratio is often unclear in the beginning and the risk of failure is high. Accordingly the employees responsible for open innovation need to have a strong intrinsic motivation for doing so and top management support is very important, too. In principle any company can do open innovation, however, the method has to fit the company's culture and its strategic goals. If this is the case money, time and effort are well spent.

\section{Literature}

Abdul-Hadi G. Abulruba and Junbae Leeb; Open innovation management: challenges and prospects. Procedia - Social and Behavioral Sciences 41 (2012) 130-138

Henry Chesbrough and Adrienne Kardon Crowther; Beyond high tech: early adopters of open innovation in other industries. R\&D Management 36_3 (2006) 229-236

Henry Lopez-Vegaa, Fredrik Tellb and Wim Vanhaverbeke; Where and how to search? Search paths in open innovation. Research Policy 45 (2016) 125-136

Amila Pilav-Velic', Olivera Marjanovic; Integrating open innovation and business process innovation: Insights from a large-scale study on a transition economy. Information \& Management 53 (2016) 398-408 Ammon Salter, Anne L. J. Ter Wal, Paola Criscuolo, and Oliver Alexy; Open for Ideation: Individual-Level Openness and Idea Generation in R\&D. Journal of Product Innovation Management 32_4 (2015) $488-504$

Andrew H. van de Ven, Douglas E. Polley, Raghu Garud and Sankaran Venkataraman; The Innovation Journey. Oxford University Press, USA (2008)

Angelika Cosima Bullinger and Kathrin Moeslein; Innovation Contests - Where are we? AMCIS 2010 Proceedings 28 (2010)

Christian Lüthje and Cornelius Herstatt; The Lead User method: an outline of empirical findings and issues for future research. R\&D Management 34_5 (2004) 553-568

Christoph Hienerth, Marion Pötz and Eric von Hippel; Exploring key characteristics of lead user workshop participants: who contributes best to the generation of truly novel solutions? DRUID Summer Conference 2007 on Appropriability, Proximity, Routines and Innovation (2007) 
Cornelius Herstatt and Eric von Hippel; FROM EXPERIENCE: Developing New Product Concepts Via the Lead User Method: A Case Study in a "Low-Tech" Field. Journal of Product Innovation Management 9 (1992) 213-221

Darryn Mitussis; SME innovation in Zhejiang, China. Journal of Knowledge-based Innovation in China 2_1 (2010) 89-105

Ellen Enkel, Annette Lenz and Reinhard Prügl; Kreativitätspotenziale aus analogen Industrien nutzen: eine empirische Analyse von Cross-Industry-Innovationsworkshops. Rationalität der Kreativität? VS Verlag für Sozialwissenschaften | GWV Fachverlage GmbH Wiesbaden (2009) 137-162

Gary L. Lilien, Pamela D. Morrison, Kathleen Searls, Mary Sonnack and Eric von Hippel; Performance Assessment of the Lead User IdeaGeneration Process for New Product Development. Management Science 48_8 (2002) 1042-1059
Hans Gersbach and Armin Schmutzler; Endogenous technological spillovers: causes and consequences. Journal of Economics \& Management Strategy 12_2 (2003) 179-205

Jens-Uwe Meyer, Innolytics Innovationsmanagement weiter denken, BusinessVillage GmbH, Göttingen (2014)

Robert Cooper and Scott Edgett; Ideation for Product Innovation: What are the best methods? PDMA Visions Magazine (2008)

Oliver Gassmann, Stephan Winterhalter and Christoph H. Wecht; Praktische Durchführung: Hürden und Tipps. Crowdsourcing - Innovationsmanagement mit Schwarmintelligenz 2. edition. Hanser Verlag München (2012) 176-194 